\title{
Molecular Studies for Putative Promoter Activity in mdh sucCDAB Operon in Sinorhizobium meliloti
}

\author{
Rateb N. Abbas ${ }^{1 *}$ and Noha M. Sorour ${ }^{2}$ \\ ${ }^{1}$ Department of Microbial Biotechnology, \\ ${ }^{2}$ Department of Industrial Biotechnology, Genetic Engineering and Biotechnology Research \\ Institute, University of Sadat City, Sadat City
}

Corresponding author: Rateb Nabil Abbas E-mail: rateb.youssef@gebri.usc.edu.eg

\begin{abstract}
The theoretical data on the malate dehydrogenase $(m d h)$, succinyl-CoA synthetase (sucCDAB) operon in Sinorhizobium meliloti and the experimental data suggest that this operon is regulated from the promoter upstream of $m d h$ gene. On the other hand, the untranslated intergenic region between the $s u c D$ and sucA genes is TA rich and could also contains active promoter site, as it was described previously in Bradyrhizobium japonicum. In this study the $m d h$ upstream region and the intergenic region between $s u c D$ and sucA were analyzed, isolated and cloned in pOT1-green fluorescence protein ( $g f p)$-fusion plasmid to examine the possibility of promoter activity. Sequences analyzed by promoter hunter program indicated that both regions have promoter sequences and transcription starting sites (TSS). In addition the measurement of the relative fluorescence units (RFU) indicated that the $m d h$ upstream region contains a constitutive promoter which was active under all tested conditions. While the intergenic region between sucD and $s u c A$ also contain active promoter site, induced only by LBmc medium and M9 medium containing glutamate as sole carbon source. The overall results suggest that $s u c A$ expression is initiated from its own upstream promoter.
\end{abstract}

Keywords: Sinorhizobium meliloti, Promoter, sucCDAB operon, Green fluorescence protein, pOTlgfp

\section{INTRODUCTION}

Sinorhizobium meliloti, has two main operons encode genes of the Tricarboxylic Acid Cycle (TCA), (Poole et al., 1999). Malate dehydrogenase $(\mathrm{MDH})$ is the first gene in an operon that also encodes the two subunits of succinylCoA synthetase $(\operatorname{suc} C D)$ and two of the three subunits of 2-oxoglutarate dehydrogenase (OGD) namely (sucAB), thus, has the structure mdh-sucCDAB. This is the same gene order reported for Rhizobium leguminosarum (Walshaw et al., 1997); Mesorhizobium loti (Kaneko et al., 2000) and Agrobacterium tumefaciens (Goodner et al., 2001). The second TCA cycle operon found in $S$. meliloti encodes for the four subunits of succinate dehydrogenase (SDH) and is structured as $s d h C D A B$ (Meek, 2013).
This arrangement is conserved across many rhizobia and is always located upstream of the $m d h-s u c C D A B$ operon. Depending on rhizobia, these two operons are separated by two open reading frames (ORFs) in Rhizobium etli (Gonzalez et al., 2006), three ORFs in $R$. leguminosarum (Young et al., 2006) and eight ORFs in S. meliloti (Galibert et al., 2001) and M. loti (Kaneko et al., 2000). The gene order mdh-sucCDAB is conserved in B. japonicum; however, a study showed that $m d h$ is expressed monocistronically and $s u c A B$ is expressed from its own upstream promoter (Green et al., 2003).

In this study, the main goal is to investigate the promoter regions controlling the expression of the $m d h$ - 
sucCDAB operon. This is achieved by testing if the sucA is expressed from its own upstream promoter or from $m d h$ upstream promotor. Therefore, the $m d h$ upstream region and the intergenic region

\section{MATERIALS AND METHODS}

2.1. Bacterial Strains, Plasmids and Growth Conditions: Bacterial strains and plasmids are listed in Table (1); Complex Luria-Bertani (LBmc) was supplemented with $2.5 \mathrm{mM} \mathrm{MgSO}_{4}, 2.5 \mathrm{mM} \mathrm{CaCl}$; the M9 medium was supplemented with 0.25 $\mathrm{mM} \mathrm{CaCl} 2,1 \mathrm{mM} \mathrm{MgSO}_{4}, 0.3 \mathrm{mg} / \mathrm{L}$ biotin, and (arabinose, malate and glutamate) as different carbon sources. Growth conditions and antibiotic concentrations were as previously described (Duncan and Fraenkel, 1979; Finan et al., 1984; Finan et al., 1986; Finan et al., 1988; Driscoll and Finan, 1993).

2.2. Sequences Analysis.

The DNA sequences for the $m d h$ sucDCAB operon were obtained from https://iant.toulouse.inra.fr/bacteria/annot ation/cgi/rhime.cgi site for Sinorhizobium meliloti 1021 complete chromosome sequence. All primers used in this study are designed using NCBI/ Primer-BLAST (primer 3) program at https://www.ncbi.nlm.nih.gov and listed in Table (2), (Untergasser et al., 2012; Ye et. al., 2012). The $m d h$ promoter and SucA putative promoter sequences were detected using Promoter Hunter program using

http://www.phisite.org/main/index.php?na v=tools\&nav_sel=hunter (Klucar et al., 2010).

\subsection{Molecular Biology Techniques}

Standard techniques were used for alkaline extraction of plasmid DNA, digestion of DNA with restriction endonucleases, DNA ligations, transformation of $\mathrm{CaCl}_{2}$ competent $E$. coli cells, and agarose gel electrophoresis (Maniatis, 1989). DNA fragments were eluted from agarose gel using the QIAEX II Gel Extraction Kit. between $s u c D$ and $s u c A$ were analyzed, isolated and cloned in pOT1-gfp fusion plasmid to examine the possibility of promoter activity.

\subsubsection{Polymerase Chain Reaction (PCR)}

All the PCR amplifications were done using the T-gradient thermocycler. The reaction conditions were the same for all primers, except that the extension time was adjusted according to the length of the targeted amplicon. The initial denaturation step was done at $95{ }^{\circ} \mathrm{C}$ for five minutes, the next 30 cycles were 30 sec of denaturation at $95{ }^{\circ} \mathrm{C}$, two minutes for the annealing at $67.5{ }^{\circ} \mathrm{C}$, and the extension at $72{ }^{\circ} \mathrm{C}$ for $90 \mathrm{sec}$ for the $m d h$ promoter fragment gene and for $50 \mathrm{sec}$ for the sucA upstream fragment amplification. Final extension was done for 10 minutes at $72{ }^{\circ} \mathrm{C}$, after which samples were retrieved and kept on ice, or in a freezer at $-20{ }^{\circ} \mathrm{C}$ until further analysis (Abbas et al., 2013; Abbas and Sorour, 2016). The PCR primers used in this study are listed in Table (2); the $m d h$, $S u c C D A B$ operon is shown in Figure (1).

2.3.2. $m d h$ and sucA Upstream Fragments Isolation and Cloning

The $m d h$ upstream region and the sucA upstream putative promoter fragments were amplified using specific PCR primers (Table 2 and Figure 2), eluted from Agarose gel and digested with PstI and HindIII restriction enzymes. Then ligated into the pOT1-gfp fusion vector separately; in forward and reverse order with the $g f p$ gene in pOT1. Finally transformed to E. coli DH5a (Maniatis, 1989) and introduced into $S$. meliloti Rm1021 via tri-parental conjugation.

\subsection{Conjugation (Tri-parental Mating)}

To mobilize the constructed plasmids pRA04, pRA05, pRA06 and pRA07, cultures of the recipient $S$. meliloti $(\mathrm{Rm}$ 1021), and donor E. coli (EcR008 to EcR012) were inoculated separately, with the mobilizer strain (MT616) and grown 
overnight $(\mathrm{O} / \mathrm{N})$ in $\mathrm{LBmc}$ with appropriate antibiotic and washed $2 \mathrm{x}$ in sterile saline. The three cultures were mixed in a 1:1:1 ratio and spotted onto LBmc agar plates. Controls were the pure cultures. Following $\mathrm{O} / \mathrm{N}$ incubation, the spot of each conjugation was scraped with a sterile needle, suspended in saline and $100 \mu \mathrm{L}$ were spread onto LBmc agar containing the appropriate selective antibiotics. Conjugation produced the $S$. meliloti strains number RN004, RN005, RN006 and RN007, respectively (Abbas et al., 2013; Abbas and Sorour, 2016).

\subsection{Green Fluorescence Protein $(g f p)$}

\section{Fusion Assays}

The $g f p$-transcriptional promoter fusion assays were done as follows; cultures were grown in triplicate, $\mathrm{O} / \mathrm{N}$ in liquid M9-media with selected carbon sources and gentamycin for plasmid maintenance.
One $\mathrm{mL}$ was put into $2 \mathrm{~mL}$ cuvette and the GFP-UV fluorescence unit was measured (excitation at $390 \mathrm{~nm}$; emission at $510 \mathrm{~nm}$ as described by Karunakaran et al. (2005) using Fluorescence Spectrophotometer (LS 45-PerkinElmer). Optical density (O.D) was adjusted at $(0.2,0.4,0.5,0.6,0.7$ and 0.8$)$ for each strain by using $0.8 \%$ saline. The fluorescence units (FU) was calculated as relative fluorescence units (RFU) using the following equations to remove the background effect of the wild type (WT) strain Rm1021.

RFU $=$ FU of strain - FU of Wild Type

\section{O.D}

2.6. Statistical analysis

All data were subjected to statistical analysis using T-test (Microsoft-Excel, $10)$ and the probability is tested at $p<0.05$.

Table 1. Bacterial strains and plasmids.

\begin{tabular}{|c|c|c|}
\hline Strain, Plasmid & Relevant Characteristics & Reference \\
\hline Escherichia coli & $\begin{array}{c}\mathrm{F}^{+} \text {endA1 hsdR17 (rk- mk-) } \\
\text { supE44 thi-1recA1 gyr96 relA1 } \\
\Delta(\operatorname{argF-lacZYA)~U169~} \text { \$80dlacZ } \\
\Delta \mathrm{M} 15 \lambda\end{array}$ & BRL Inc. \\
\hline MT616 & DH5a, mobilizer strain, $\mathrm{Cm}^{\mathrm{r}}$ & Finan et.al.1986. \\
\hline EcR008 & DH5a $\lambda$ pir+ pOT1Gmr, gfp fusion & Lab Strain \\
\hline EcR009 & $\begin{array}{l}\text { DH5a } \lambda \text { pir+ pOT1 carrying } \\
\text { partial mdh and promoter area- } \\
\text { gfp fusion, forward orientation }\end{array}$ & Present Study \\
\hline EcR010 & $\begin{array}{l}\text { DH5a } \lambda \text { pir+ pOT1 carrying } \\
\text { partial } m d h \text { and promoter area- } \\
\text { gfp fusion, reverse orientation }\end{array}$ & Present Study \\
\hline EcR011 & $\begin{array}{l}\text { POT1 carrying partial sucA and } \\
\text { putative promoter area-gfp } \\
\text { fusion, forward orientation }\end{array}$ & Present Study \\
\hline EcR012 & $\begin{array}{l}\text { POT1 carrying partial sucA and } \\
\text { putative promoter area-gfp } \\
\text { fusion, reverse orientation }\end{array}$ & Present Study \\
\hline
\end{tabular}




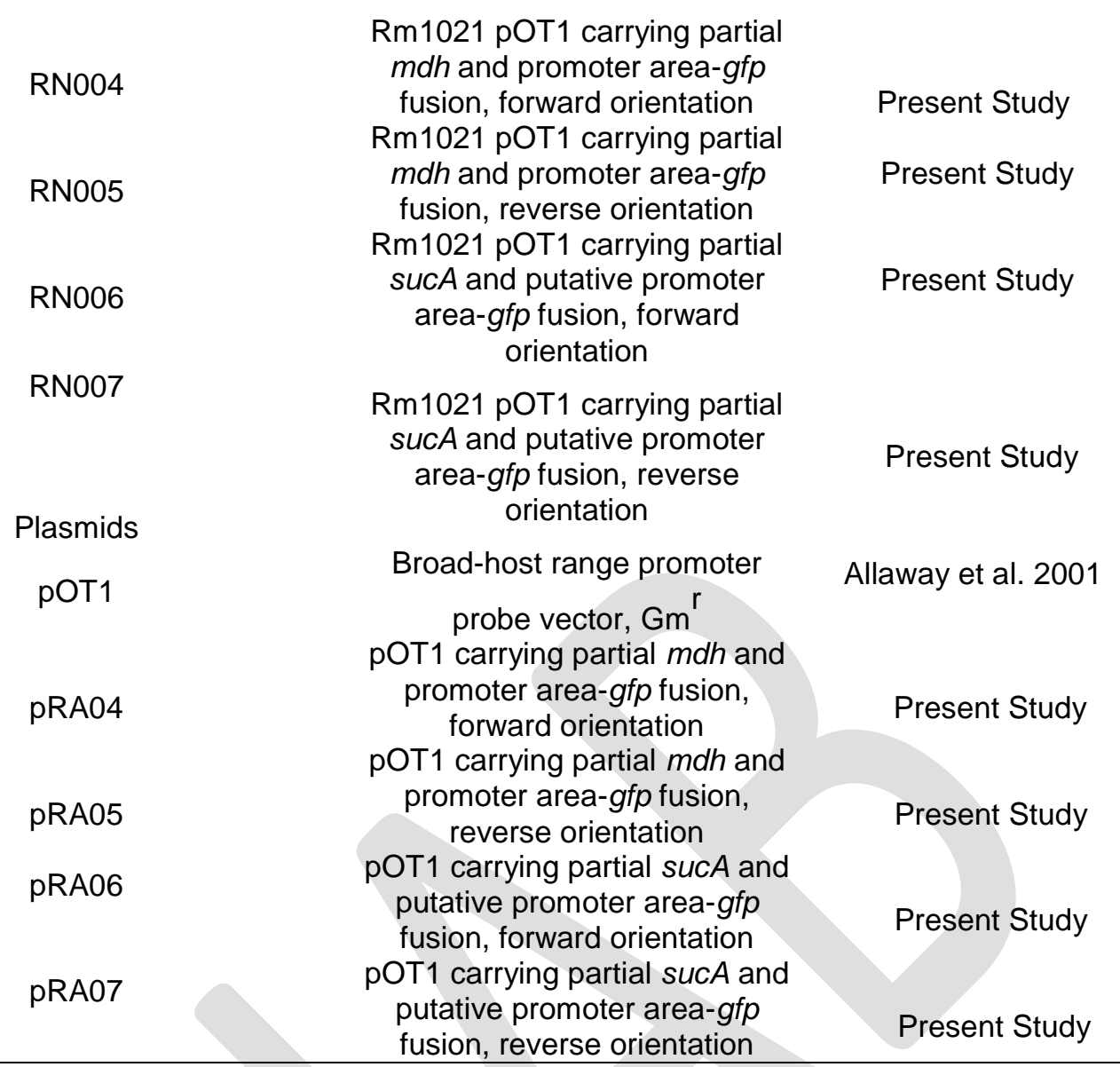

Table 2. Primers sequences.

\begin{tabular}{ccc}
\hline Primer & Sequence & Orientation \\
\hline $\begin{array}{c}\text { mdh Forward } \\
m d h \text { Reverse }\end{array}$ & 5'-GACTGCAGTCCGGCGACATCA-3' & mdh upstream fragment \\
& 5'-TTGGAAGCTTGGTCCAACCCATCTG-3' & gfp fusion forward \\
sucA Forward & 5'-GCCTGCAGTCAACGCCGAGGTC-3' & mdh upstream fragment \\
sucA Reverse & 5'-GGCAAGCTTGATGCCGATGTAGA-3' & gfp fusion forward \\
\hline Each primer contains Pst1 and Hindlll restriction sites and it was reversed for cloning in reverse order with gfp fusion.
\end{tabular}

\section{RESULTS AND DISCUSSION} 3.1. $m d h, S u c D C A B$ Operon Sequences Analyses

The $m d h$, SucDCAB operon structure is shown in Figure (1), illustrating intergenic region between $m d h$ and the upstream ORF SMc02478 and between the sucA and $s u c D$ gene. The Promoter Hunter program found a Promoter region predicted for the upstream sequence of $m d h$ gene with 0.80 score cutoff (Score range 0 to 1 ). The Transcription starting site (TSS) is shown in larger font, as shown in the following sequence. The $m d h$ promoter location for the 1001 base tested sequence start at 86 and ends at 131 with 0.81 score (Figure 1).

While, the 1001 base upstream of sucA was tested and it showed probable promoter region with TSS and 0.80 score 
cutoff. The transcription starting site (TSS) shown in larger font. Promoter predictions for the 1001 base upstream the sucA sequence start at 680 and ends at 725 with 0.96 score (Figure 1).

Results suggested that, the existence of upstream promoter for sucA gene is highly probable and it could be transcribed as monocistronic as it was previously described in B. japonicum (Green et al., 2003) for which evidence suggested that $s u c A$ expression is initiated from its own upstream promoter.

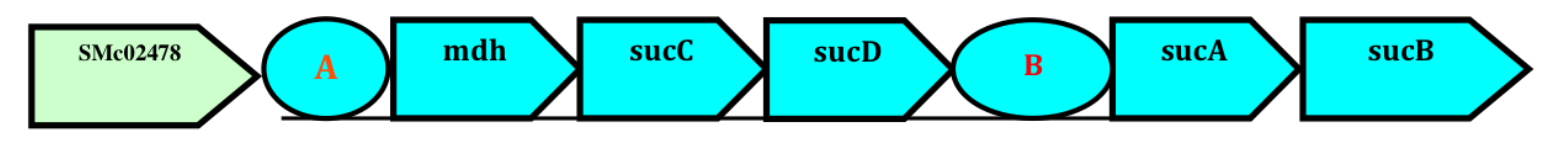

1

CCCGCAAAATTCAGCGGCGGAATGACGGTCCGGCGACATCAGTTCTTACGTTTACGTAAGAGGTTTGGCGTTTGCCGCGTTT CAGgCcttgatcAttTtGgGatcacaAaG.

\section{2}

ACGAAGCCCCTCACGGTCTGCCGATCGCTGGAGCACTTCCAGGAAAGTGCCGTTTGAAGGACGCGCAGAACACCG CGGCTATGCTCACCACTATAACGA.

Figure 1. Diagram of $m d h$, SucCDAB operon A: is a promoter located upstream of $m d h$ ORF SMc02478, while B: is intergenic region that may contain other promoter for SucA gene for the individual expression regulation. 1: is the detected sequence for the putative $m d h$ upstream promoters with TSS labeled in red and 2: is the detected sequence for the putative sucA upstream promoters with TSS labeled in red.

\subsection{Detection of $m d h$ and sucA upstream cloned fragments}

The plasmids containing the $m d h$ promoter and the sucA upstream putative promoter fragments were re-isolated and digested with PstI and HindIII enzymes to confirm if it is carrying the desired fragments (Figure 2), before introducing into the host $S$. meliloti strain Rm1021 via conjugation to produce RN004, RN005, RN006 and RN007 carrying the pRA04 to pRA07, respectively. The transformed $S$. meliloti strains were also tested to confirm that it is carrying the desired fragments before measuring the promoter activity. All transformed $S$. meliloti strains were containing the pOT1 plasmid with the right fragment as shown in Figure (3).

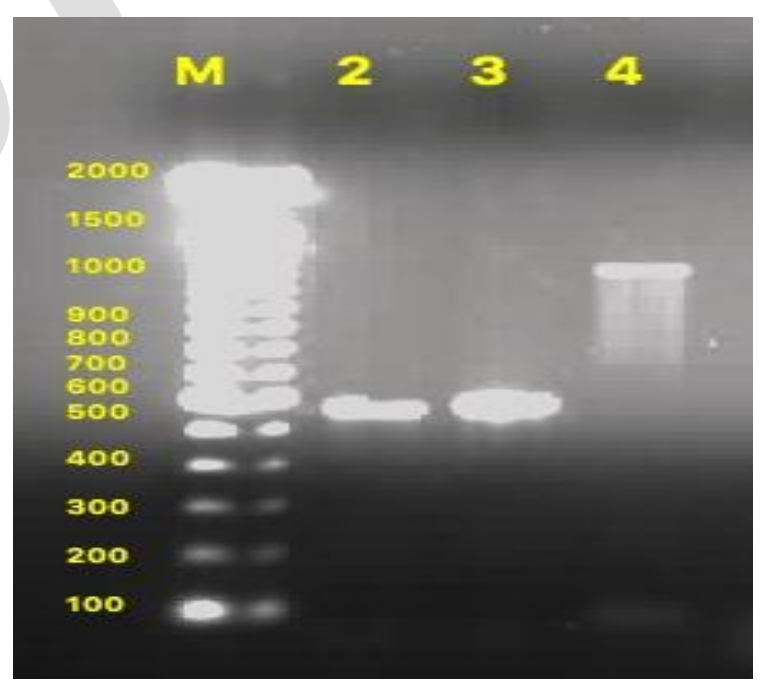

Figure 2. The PCR products of the mdh upstream fragment at lanes 2 and 3; lane 4 has SucA upstream fragment and lane $M$ is $100 \mathrm{bp}$ DNA ladder. 


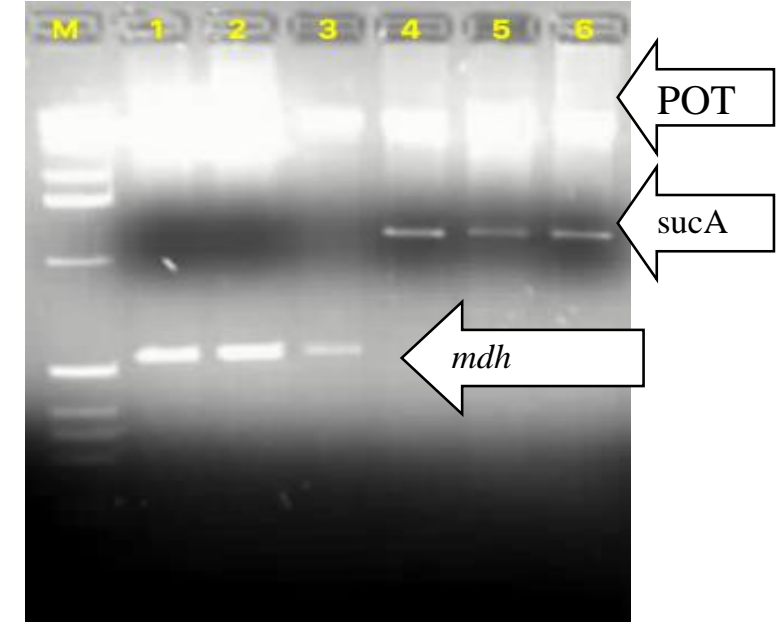

Figure 3. Confirmation of $m d h$ and $s u c A$ upstream fragment cloned in gfp-pOT1 vector and digested with Pst1 and HindIII restriction enzymes. Lane M is $1 \mathrm{kbp}$ ladder, lanes 1 to 3 is $m d h$ upstream fragment digested from gfp-pOT1 and lanes 4 to 6 sucA upstream fragment digested from gfp-pOT1.

\subsection{Detection of Promoters Activities of mdh, sucCDAB Operon}

To ascertain whether the area directly upstream of $m d h$ and $s u c A$ is the functional promoter for the $m d h-s u c C D A B$ operon, a transcriptional $g f p$-gene fusion was made. A 500 nucleotide (nt) fragment comprising approximate $300 \mathrm{nt}$ upstream of $m d h$ and $200 \mathrm{nt}$ of $m d h$ was cloned into the vector pOT1 in forward orientation resulting in plasmid pRA04. As a control, the same fragment was ligated in reverse orientation relative to $g f p$ resulting in plasmid pRA05. Plasmids were mobilized into the Rm1021 by triparental mating resulting in strains RN004 and RN005, respectively. Cultures were grown in LBmc and M9-minimal media containing arabinose, glutamate and malate, as sole carbon sources. In the same way, Rm1021 WT strains were transformed with plasmids carrying a $g f p$-gene fused into sucA upstream region in the forward and reverse orientations to determine if there was an active promoter upstream the region of sucA gene. In this case, a $1000 \mathrm{nt}$ fragment comprising the $300 \mathrm{nt}$, intergenic region between $s u c D$ and $s u c A$ and approximately $700 \mathrm{nt}$ of $s u c A$ were ligated into the vector pOT1 in both forward and reverse orientations relative to $g f p$ resulting in plasmids pRA06 and pRA07, respectively. Plasmids were mobilized into the Rm1021 by triparental mating resulting in strains RN006 and RN007, respectively, cultures were grown under the same conditions as above, and the fluorescence was measured as RFUs, (Figures 4 and 5). Results presented in Figure (4) showed that strains RN005 and RN007 carrying the reverse $m d h$ and $s u c A$ upstream fragments, respectively, have the same WT RFUs level at all tested conditions. On the other hand, strain RN004 with the $m d h$ upstream forward fragment had RFU significantly $(p<0.05)$ higher than those obtained from strain RN006 sucA upstream forward fragment in both M9 glutamate and arabinose but equal to it in the M9 malate medium. While the strain RN006 with the sucA upstream forward fragment had RFUs significantly $(p<0.05)$ higher than strain RN004 with the $m d h$ upstream forward fragment under LBmc test conditions (Figure 5), indicating that the promoter of this operon is located directly upstream of $m d h$ gene and is working in all tested conditions (arabinose, glutamate, malate and LBmc) (Walshaw et al., 1997). While the intergenic region between sucD and sucA could contain active promoter working under glutamate and LBmc test conditions only. These results suggest that the upstream promoter of $m d h$ gene is a constitutive promoter while the putative sucA upstream promoter could be an inducible one and is activated under certain conditions (Dillewijn et al., 2001; Green et al., 2003; Zhou et al., 2006; Geetha and Joshi, 2013). Other suggestion proposed by Meek (2013), is that when S. meliloti has been differentiated into bacteroids, the putative sucA promoter could be functional in the Alfalafa plant, however more investigations are needed to discover it in details. 

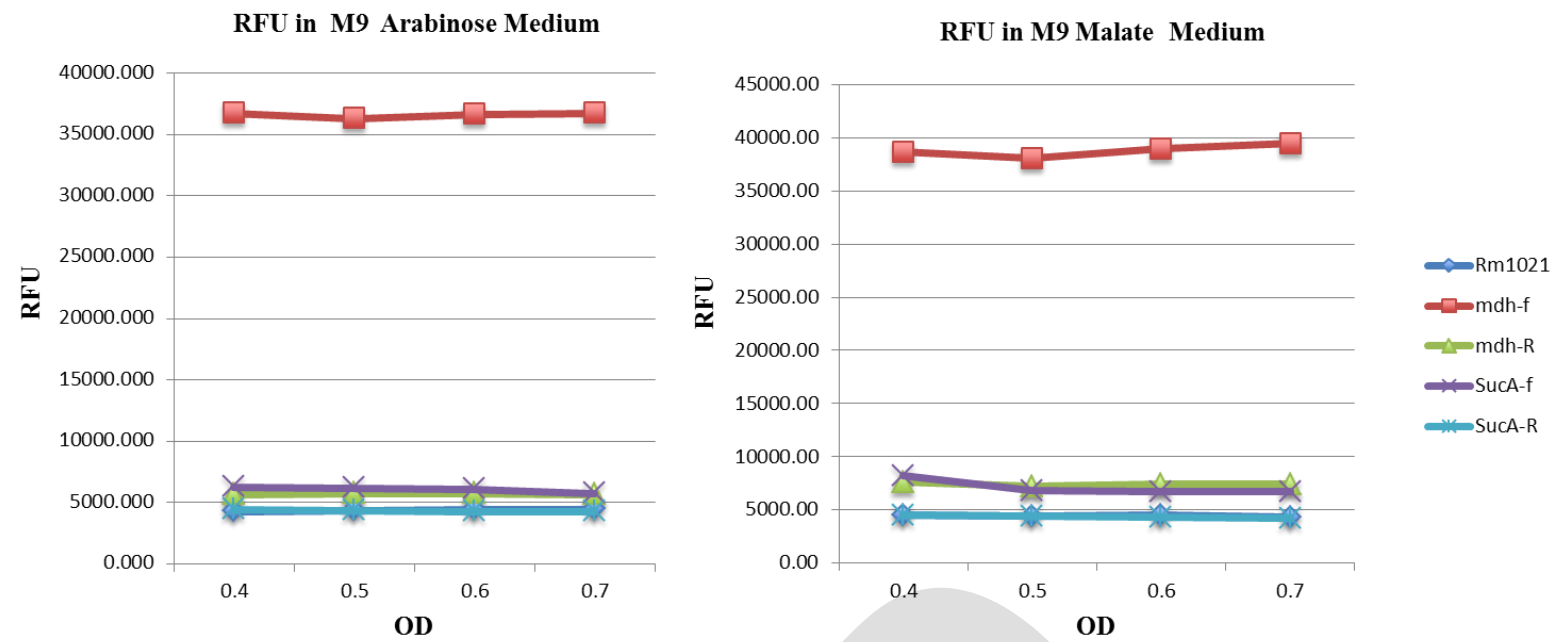

Figure 4. The Relative Fluorescence Units (RFU) of the S. meliloti tested strains with M9 Arabinose (left) and M9 Malate (right) as sole carbon sources, RN004 (mdh-f), RN005 (mdh-R), RN006 (sucA-f) and RN007 (suCA-R) and Rm1021(WT).
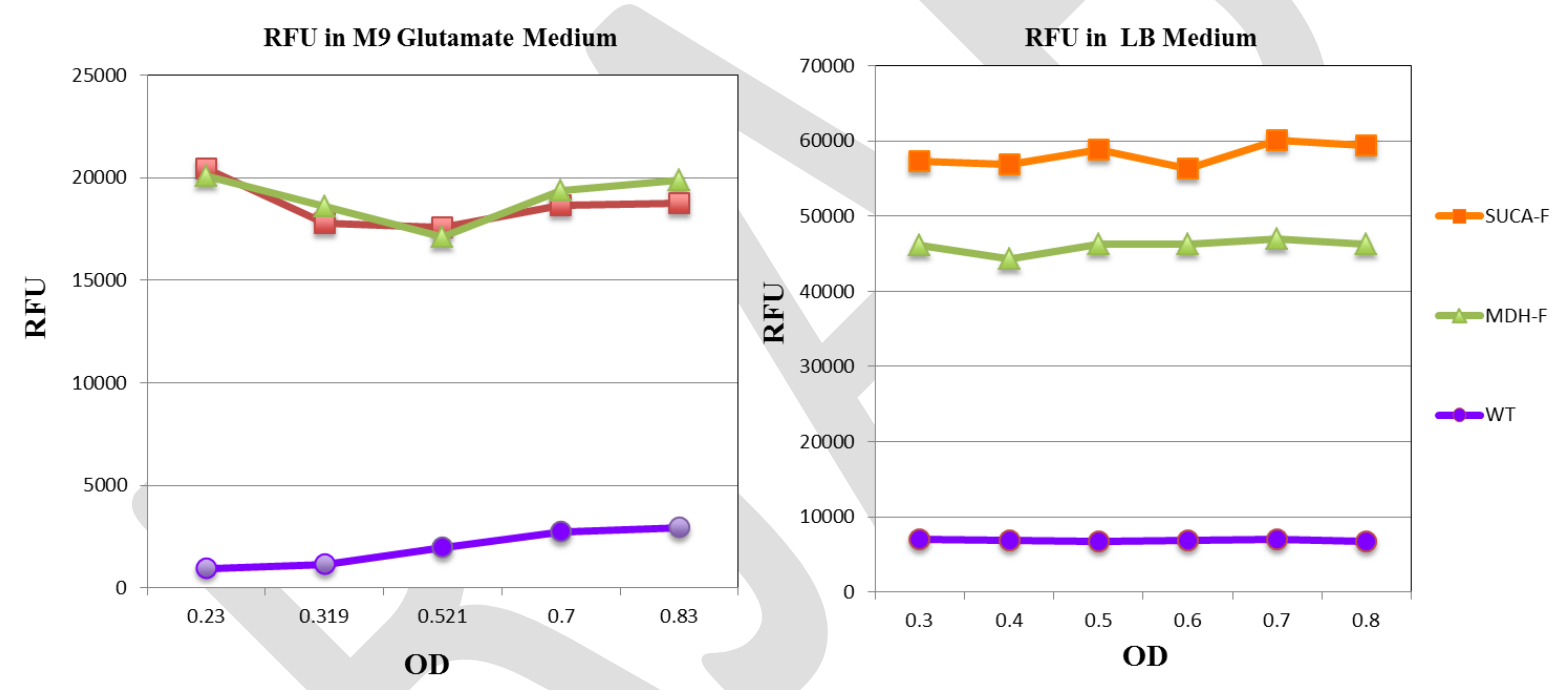

Figure 5. The Relative Fluorescence Units (RFU) of the S. meliloti tested strains under M9 Glutamate medium (left) and LBmc medium (right), RN004 (mdh-f), RN006 (sucA-f) and Rm1021(WT).

\section{CONCLUDING REMARKS}

- S. meliloti, expresses the mdh-sucCDAB operon from a promoter upstream of $m d h$.

- $\operatorname{sucA}$ gene expression is initiated from its own upstream promoter, whether this indicated that $\operatorname{sucA}$ has a functioning inducible promoter that needs further investigation especially when $S$. meliloti has been differentiated into bacteroids form in the Alfalfa plant.

- No activity for the reverse $m d h$ and sucA promoter fragments was observed, which indicates that no promoter sequences in the negative strand. 


\section{REFERENCES}

Abbas, R.N. and Sorour, N.M. (2016). Molecular and functional characterization of the Ipda2 gene in Sinorhizobium meliloti. Menoufia Journal of Agricultural Biotechnology. 1:23-35

Abbas, R.N., Babic, B., Poilly, M., Meek, D. and Driscoll, B. (2013). Molecular and functional characterization of the Ipda1 gene in Sinorhizobium meliloti. Egypt. J. Genet. Cytol. 42:405-16.

Allaway, D., Schofield, N.A., Leonard, M.E., Gilardoni, L., Finan, T.M. and Poole, P.S., (2001). Use of differential fluorescence induction and optical trapping to isolate environmentally induced genes. Environ. Microbiol. 3: 397-406.

Dillewijn, V.P., Soto, M.J., Villadas, P.J. and Toro, N. (2001). Construction and environmental release of a Sinorhizobium meliloti strain genetically modified to be more competitive for alfalfa nodulation. Appl. Environ. Microbiol. 67(9):3860-5.

Driscoll, B.T. and Finan, T.M. (1993). NAD ${ }^{+}$ dependent malic enzyme of Rhizobium meliloti is required for symbiotic nitrogen fixation. Molecular Microbiology, 7:865-73.

Duncan, M.J. and Fraenkel, D.G. (1979). AlphaKetoglutarate dehydrogenase mutant of Rhizobium meliloti. Journal of Bacteriology, 137:415-9.

Finan, T.M., Kunkel, B.A., De Vos, G.F. and Signer, E.R. (1986). Second symbiotic megaplasmid in Rhizobium meliloti carrying exopolysaccharide and thiamine synthesis genes. J. Bacteriol. 167:66-72.

Finan, T.M., Hartweig, E., LeMieux, K., Bergman, K., Walker, G.C. and Signer, E.R. (1984). General transduction in Rhizobium meliloti. J. Bacteriol. 159:120-4.

Finan, T.M., Oresnik, I.V., and Bottacin, A.N. (1988). Mutants of Rhizobium meliloti defective in succinate metabolism. J. Bacteriol. 170:3396-403.

Galibert, F., Finan, T.M., Long, S.R., Puhler, A., Abola, P., Ampe, F., Barloy Hubler, F., Barnett, M.J., Becker, A., Boistard, P., Bothe, G., Boutry, M., Bowser, L., Buhrmester, J., Cadieu, E., Capela, D., Chain, P., Cowie, A., Davis, R.W., Dreano,
S., Federspiel, N.A., Fisher, R.F., Gloux, S., Godrie, T., Goffeau, A., Golding, B., Gouzy, J., Gurjal, M., Hernandez Lucas, I., Hong, A., Huizar, L., Hyman, R.W., Jones, T., Kahn, D., Kahn, M.L., Kalman, S., Keating, D.H., Kiss, E., Komp, C., Lelaure, V., Masuy, D., Palm, C., Peck, M.C., Pohl, T.M., Portetelle, D., Purnelle, B., Ramsperger, U., Surzycki, R., Thebault, P., Vandenbol, M., Vorholter, F.J., Weidner, S., Wells, D.H., Wong, K., Yeh, K.C. and Batut, J., (2001). The composite genome of the legume symbiont Sinorhizobium meliloti. Science, 293: 668672.

Geetha, S.J. and Joshi, S.J. (2013). Engineering rhizobial bioinoculants: A strategy to improve iron nutrition. Scientific World Journal, 6; 3158-90.

Gonzalez, V., Santamaria, R.I., Bustos, P., Hernandez Gonzalez, I., Medrano Soto, A., Moreno Hagelsieb, G., Janga, S.C., Ramirez, M.A., Jimenez Jacinto, V., Collado Vides, J. and Davila, G. (2006). The partitioned Rhizobium etli genome: genetic and metabolic redundancy in seven interacting replicons. Proc. Natl. Acad. Sci. USA. 103: 3834-3839.

Goodner, B., Hinkle, G., Gattung, S., Miller, N., Blanchard, M., Qurollo, B., Goldman, B.S., Cao, Y., Askenazi, M., Halling, C., Mullin, L., Houmiel, K., Gordon, J., Vaudin, M., lartchouk, O., Epp, A., Liu, F., Wollam, C., Allinger, M., Doughty, D., Scott, C., Lappas, C., Markelz, B., Flanagan, C., Crowell, C., Gurson, J., Lomo, C., Sear, C., Strub, G., Cielo, C. and Slater, S. (2001). Genome sequence of the plant pathogen and biotechnology agent Agrobacterium tumefaciens C58. Science, 294: 2323-2328.

Green, L.S., Waters, J.K., Ko, S. and Emerich, D.W. (2003). Comparative analysis of the Bradyrhizobium japonicum sucA region. Canadian Journal of Microbiology, 49: 237-243.

Kaneko, T., Nakamura, Y., Sato, S., Asamizu, E., Kato, T., Sasamoto, S., Watanabe, A., Idesawa, K., Ishikawa, A., Kawashima, K., Kimura, T., Kishida, Y., Kiyokawa, C., Kohara, M., Matsumoto, M., Matsuno, A., Mochizuki, Y., Nakayama, S., Nakazaki, N., Shimpo, S., Sugimoto, M., Takeuchi, 
C., Yamada, M. and Tabata, S. (2000). Complete genome structure of the nitrogen fixing symbiotic bacterium Mesorhizobium loti. DNA Res. 7: 331-338.

Karunakaran, R., Mauchline, T.H., Hosie, A.H. and Poole, P.S. (2005). A family of promoter probe vectors incorporating autofluorescent and chromogenic reporter proteins for studying gene expression in Gram negative bacteria. Microbiology, 151: 3249-3256.

Klucar, L., Stano, M. and Hajduk, M. (2010). phiSITE: database of gene regulation in bacteriophages. Nucleic Acids Research, 38 (Database issue), D366-D370. http://doi.org/10.1093/nar/gkp911.

Liu, Z., Tyo, K.E.J., Martínez, J.L., Petranovic, D. and Nielsen, J. (2012). Different Expression Systems for Production of Recombinant Proteins in Saccharomyces cerevisiae. Biotechnology and Bioengineering, 109(5), 1259-1268.

Maniatis, T. (1989). Molecular cloning: a laboratory manual. In: Sambrook, J., et al. (Eds.) Cold Spring Harbor Laboratory Press, New York.

Meade, H.M., Long, S.R., RuvKin, G.B., Brown, S.E. and Ausubel, F.M. (1982). Physical and genetic characterization of symbiotic and auxotrophic mutants of Rhizobium meliloti induced by transposon $\operatorname{Tn} 5$ mutagenesis. J. Bacteriol. 149: 114-122.

Meek, D. (2013).The biochemical and genetic characterization of the TCA cycle in Sinorhizobium meliloti. Ph.D. Thesis, Department of Natural Resource Sciences, McGill University, Montreal, Canada.
Poole, P., Reid, C., East, A., Allaway, D., Day, M. and Leonard, M. (1999). Regulation of the mdh sucCDAB operon in Rhizobium leguminosarum. FEMS Microbiol. Lett. 176: $247-255$.

Untergasser, A., Cutcutache, I., Koressaar, T., Ye, J., Faircloth, B.C., Remm, M. and Rozen, S.G. (2012). Primer3 - new capabilities and interfaces. Nucleic Acids Research, 40(15):115.

Walshaw, D.L., Wilkinson, A., Mundy, M., Smith, M. and Poole, P.S. (1997). Regulation of the TCA cycle and the general amino acid permease by overflow metabolism in Rhizobium leguminosarum. Microbiology, 143: 2209-2221.

Ye, J., Coulouris, G., Zaretskaya, I., Cutcutache, I., Rozen, S. and Madden, T.L. (2012). Primer-BLAST: A tool to design targetspecific primers for polymerase chain reaction. BMC Bioinformatics, 13, 134.

Young, J.P., Crossman, L.C., Johnston, A.W., Thomson, N.R., Ghazoui, Z.F., Hull, K.H., Wexler, M., Curson, A.R., Todd, J.D., Poole, P.S., Mauchline, T.H., East, A.K., Quail, M.A., Churcher, C., Arrowsmith, C., Cherevach, I., Chillingworth, T., Clarke, K., Cronin, A., Davis, P., Fraser, A., Hance, Z., Hauser, H., Jagels, K., Moule, S., Mungall, K., Norbertczak, H., Rabbinowitsch, E., Sanders, M., Simmonds, M., Whitehead, S. and Parkhill, J. (2006). The genome of Rhizobium leguminosarum has recognizable core and accessory components. Genome Biol. 7: R34.

Zhou, Y., Shi, T., Mozola, M.A., Olson, E.R., Henthorn, K., Brown, S. and Friedman, D.I. (2006). Evidence that the Promoter Can Influence Assembly of Antitermination Complexes at Downstream RNA Sites. Journal of Bacteriology, 188(6), 22222232. 